\title{
Mathematical Modeling of Cable - Stayed Bridge
}

\author{
Yuanfu Mao
}

(Nanchang Institute of Science \& Technology, Nanchang 330108)

\begin{abstract}
Keywords: Multi-tower cable-stayed bridge; Geometrical nonlinear material; Nonlinearity; Stiffness
\end{abstract}
\begin{abstract}
In the bridge design across the river, the cable-stayed bridge has become a very competitive bridge type. As the bridge instability occurred, the cable-stayed bridge instability problem is also of concern. In recent years, in order to meet the needs of production and life, multi-tower cable-stayed bridge has also emerged. In the multi-tower cable-stayed bridge due to the increase in the tower, the tower is not easy to control the displacement, making the already flexible structure of the cable-stayed bridge becomes softer. The possibility of instability is increased, so it is necessary to study the stability of multi-tower cable-stayed bridge. The first part introduces the research history of bridge stability analysis at home and abroad, and points out that many bridges are damaged due to instability, and the necessity of stability analysis is expounded. Then we introduce the nonlinear factors that affect the stability of the cable - stayed bridge, which introduces the causes of these factors, the mathematical calculation methods, and how to eliminate these unfavorable factors. Finally, the method of stability analysis of cable - stayed bridge is put forward, which is divided into simplified method and accurate calculation method.
\end{abstract}

\section{Introduction}

Cable-stayed bridges are one of the common bridge type of highway bridge, and they are favored by bridge designers with its larger span and beautiful shape. With the continuous improvement of the theory of structure design and computer technology, the continuous development of new materials and technology and the continuous improvement of construction technology, the cable-stayed bridges are very fast and the span grows. Because the cable-stayed bridges have long span, good anti-seismic performance, material saving, good rigidity and so on, in our country has been built and under construction across rivers and across the Sea Bridge has occupied the dominant position, in order to safeguard national production and normal life played an important role. But the structure design not only satisfies the rigidity, the strength requirement also satisfies the need of stability. The structural stiffness reaction is the ability of the structure to resist deformation, and the strength reaction is the ability of structural resistance to destroy. After the completion of structural design, it is absolutely not only because the stiffness, strength of the calculation of the need to meet the definition of security, but also to check the stability. This paper focuses on the stability analysis based on the introduction of geometric nonlinearity and material nonlinearity, and the calculation obtains the stability coefficient and compares the parameters given by the relevant specifications.

\section{Research on Stability Analysis of Cable - Stayed Bridge}

In the early construction of cable-stayed bridges, people are concerned about the strength and stiffness of the study, think that as long as the structural checking, considering the ultimate bearing capacity to meet the strength theory requirements, do not occur strength damage, while in normal use state without large deformation can. Subsequently, as the bridge instability accidents occur frequently, after checking that the structure in the internal stress is still far from the strength of failure to achieve according to the theory of the internal force will also occur because of instability and damage, and found that stability problems become not negligible, cable-stayed bridges to be considered in the study of the problem. The stability of the structure can be judged by static criterion, energy criterion and motion criterion. Engineering experience shows that the institutions that are not in equilibrium and stable, the principle of the stability of the structure is judged by using 
the energy method: the size of the total potential energy of the elastic system in equilibrium position has a great relationship with the stable state of the structure, wherein the structure of total potential energy is in a stable equilibrium and is in unstable equilibrium at the maximum time. The stability of the equilibrium is illustrated by the three different equilibrium positions of the small steel balls in Figure 1 below:

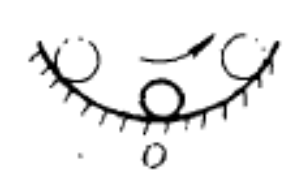

a)

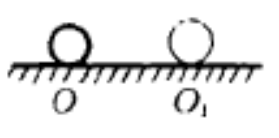

b)

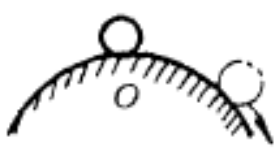

c)

Fig.1 Diagram of the Ball at Three Different Equilibrium Positions

The three small balls in the figure are in equilibrium, but the stability is not the same. For a small ball in Figure a, when the ball with a small interference after the ball temporarily leave the origin of the same time its potential energy increases, once the withdrawal of interference, the ball under the action of potential energy can be restored to the origin, so this balance is stable; Figure $b$ of the ball after the interference away from the origin, interference removed after the stay in the new position This state is called the neutral balance state, or that with the balance state, it can be said to be from the stable balance to the unstable balance critical state. In Figure C, after the ball interferes away from the origin, the potential energy is reduced, remove the interference after the ball potential energy has been transformed into kinetic energy, the ball can not only return to the original origin but continue to scroll down, away from the origin, so this equilibrium state is unstable.

Limited by the immature non-linear analysis theory and the low level of computer development, the stability analysis of the early-stayed bridges only stays in the first kind of stability analysis, later with the perfection of nonlinear theory and the development of computational tools, the second type of stability research is gradually enriched.

\section{Sag Effect of the Cable}

The geometric nonlinear theory can be divided into two kinds of the finite displacement theory and the large displacement strain theory, namely the finite strain theory. In general, in most of the large displacement problems, the internal strain of the structure is tiny. It is only possible to encounter a large strain in the case of nonlinear factors, and the yield strength of the steel wire made by the high-strength cable is far higher than the yield strength of the steels used in the main girder, and the large strain cannot occur under the design load.

To take full account of the effect of such effects on structural mechanics, it is necessary to consider the effect of modeling in the structure, making the analysis of the structure more real. At present, the commonly used methods of simulating sag effect are as follows.

Equivalent Elastic Modulus Method

This method was first proposed by ALSPippard and L. Chitty in 1944, and later Ernst and Pdeolny used a rod element to simulate a cable in the calculation of the cable-stayed bridge with an elastic modulus of elastic modulus to make a reduction. The Ernst formula for considering the sag effect by modifying the elastic modulus of the cable is as follows:

$$
\mathrm{E}_{\text {eq }}=\frac{E}{1+\frac{w^{2} l_{x}^{2}}{12 A^{2} \sigma^{3}} E}
$$

In the above formula, $\mathrm{E}_{\mathrm{eq}}$ refers to the modified elasticity modulus, Ix refers to the projection length of the cable in the horizontal direction, E refers to the natural cable elastic modulus, W refers to the weight of per unit of cable, A refers to the sectional area of wire in cable, a refers to stress in cable. Ernst indicates that the use of high-strength wire rods to improve the working stress of the cable, the use of light and effective means of cable protection, so that the weight of each extension 
of the cable is smaller, all contribute to improving the cable stiffness and reducing the linear effect.

Multi - Section Method

When the equivalent elastic modulus method is used, the cable is regarded as the straight rod, and the actual situation is simulated by considering the sag effect by correcting the elastic modulus of the cable. For the introduction of sag effect on the cable can also be directly from the geometric simulation of the cable changes, that is, a cable is divided into multi-segment, each segment connected by defining a number of rod elements to describe the middle of the cable node Motion trajectory, to achieve the effect of simulated sag effect.

\section{A Simplified Method for Calculating the Stability of Cable - Stayed Bridges}

For the elastic bridge simply erected at both ends, the axial pressure of the beam end exceeds the critical pressure, then the buckling produces a number of half waves, taking a half wave to study, take the half-wave center as the origin of the coordinates, the buckling mode approximates the sinusoid curve:

$$
\mathrm{y}=y_{0} \cos \frac{\pi x}{l}
$$

The equivalent elastic modulus of elastic support can be expressed as:

$$
\beta=\frac{K}{a}
$$

Where $\mathrm{k}$ is the stiffness of the spring and a is the spacing of the springs.

The elastic support reaction force is proportional to the size of the deflection

The cosine curve's node shear force is:

$$
\mathrm{dR}=\text { Pydx }
$$

$$
Q=\int_{0}^{\frac{1}{2}} \mathrm{dR}=\frac{\beta y_{0} l}{\pi}
$$

The midpoint moment is:

$$
\mathrm{M}_{0}=\mathrm{Py}_{0}-\frac{Q l}{2}+\int_{0}^{\frac{1}{2}} x d R=P y_{0}-\frac{\beta y_{0} l^{2}}{2 \pi}+\beta y_{0} l^{2}\left(\frac{1}{2 \pi}-\frac{1}{\pi^{2}}\right)
$$

Taking into account the boundary conditions:

$$
\text { Ely }\left.\right|_{\mathrm{x}=0}=-M_{0}=-E l y_{0} \frac{\pi^{2}}{l^{2}}
$$

Then get:

$$
\mathrm{P}=\frac{\pi^{2} \mathrm{EI}}{1^{2}}+\frac{\beta 1^{2}}{\pi^{2}}
$$

It can be obtained from $\mathrm{dPIdL}=0$ that when the $\mathrm{P}$ value is the minimum,

$$
1=\pi^{4} \sqrt{E I / \beta}
$$

The main girder of the cable-stayed bridge can be approximated as a continuous beam, so its critical force $\mathrm{N}_{\mathrm{c} r}$ can be modeled by the continuous beam method. For the equivalent spring stiffness $\mathrm{k}$ of the cable,

$$
\mathrm{k}=\frac{1}{\delta_{1}+\delta_{2}}
$$

$\delta_{1}, \delta_{2}$ are the vertical displacement components generated by the displacement of the cable and the tower on the main beam. 


\section{Finite Element Method for Stability Calculation of Cable-Stayed Bridge}

In solid mechanics, in-depth discussion has been carried out. The calculation of the first type of stability requires that the structure must have no initial defects and must be fully axially compressed. Euler formula of the center compression bar is:

$$
\mathrm{P}_{\mathrm{cr}}=\frac{\pi^{2} E I}{(u l)^{2}}
$$

In the formula above, $\mathrm{P}_{\mathrm{cr}} \longrightarrow$ Euler critical force

EI-Bar stiffness

M-Constraint coefficient

In the above formula, the bearing capacity of the bar is related to the constraint of the two ends of the bar, the better the constraint condition, the smaller the constraint coefficient, and the greater the carrying capacity of the bar.

The finite element equilibrium equation is used to describe the physical phenomena of structural instability. In the T.L. formula, the equilibrium equation for the structural incremental form is:

$$
\left({ }^{0}[\mathrm{~K}]_{0}+{ }^{0}\left[\mathrm{~K}_{\sigma}\right]+\left[{ }^{0} \mathrm{~K}_{\mathrm{L}}\right]\right)\{\Delta \mathrm{U}\}=\left[{ }^{0} \mathrm{~K}\right]_{\mathrm{T}}\{\Delta \mathrm{U}\}=\{\Delta \mathrm{R}\}
$$

The above equation is used to solve the stability problem in the ideal state. The eigenvalue and the buckling mode are obtained by solving the equation, which can describe the eigenvalue stability of the structure completely. In the engineering practice, due to the initial bending and eccentricity of the initial defects and manufacturing errors, the first kind of stabilization problem occurs only in the ideal state, and the first type of instability does not occur in the actual engineering state Can be the second type of instability.

\section{Conclusion}

The results of this paper are as follows: (1) The nonlinear analysis theory is introduced, and the non-linear factors influencing the construction and use of the cable-stayed bridge are pointed out. The geometric nonlinear factors and material nonlinear factors cannot be neglected. The effect of large bending effect of bending effect is the existence of the large displacement effect, geometric nonlinearity is inevitable. If the ultimate bearing capacity of the structure at the time of material failure is considered, the nonlinearity of the material must be taken into account. The paper analyzes the causes of these factors, and puts forward the method of solving them by using mathematical formula. (2)The theory of stability analysis of cable - stayed bridge is introduced. The mathematical equations of two kinds of stable analysis are given. Two kinds of stable analysis methods are introduced. The stability criterion of cable - stayed bridge is introduced, and the theoretical basis is put forward for engineering analysis. (3) The process of modeling the structure of the bridge is introduced in detail. It is pointed out how the main beam unit, the main tower, the cable and the rigid arm are simulated. It is pointed out that the accurate model is the prerequisite for accurate calculation.

\section{Acknowledgements}

Project Funding: Science and technology research project of Jiangxi Provincial Department of Education (No.GJJ151244)

\section{References}

[1] B. O. R, A. M. M. Non-Linear Static and Modal Analysis of Three Types of Cable-Stayed Bridges[J]. Mathematical Theory \& Modeling, 2013.

[2] Čaušević M, Bulić M. Cable-stayed Bridge Resonance with Cables: Dubrovnik Bridge Case Study[C]// IABSE-IASS SYMPOSIUM Taller, Longer, Lighter. Hrvatska znanstvena bibliografija i MZOS-Svibor, 2011. 
[3] Kanok-Nukulchai W, Hong G. Nonlinear modelling of cable-stayed bridges[J]. Journal of Constructional Steel Research, 1992, 26(2):249-267.

[4] Chen Y, Zhou H. Modelling of Cable-Stay Bridges for Dynamic Analysis[J]. Zhongguo Tiedao Kexue, 1995.

[5] Papatheodorou, Marianthi. Dynamic finite element modelling, measurement and updating of cable stayed bridges[D]. University of Bristol, 2001.

[6] Geng F, Ding Y, Li A. Passive Control System for Mitigation of Longitudinal Buffeting Responses of a Six-Tower Cable-Stayed Bridge[J]. Mathematical Problems in Engineering, 2016, 2016(1):1-18.

[7] Zhu Q, Xu Y L, Xiao X. Multiscale Modeling and Model Updating of a Cable-Stayed Bridge. I: Modeling and Influence Line Analysis[J]. Journal of Bridge Engineering, 2015, 20(10):04014112.

[8] Quiel S, Yokoyama T, Mueller K, et al. Mitigating the effects of a tanker truck fire on a cable-stayed bridge[C]// International Conference on Performance-based and Life-cycle Structural Engineering. 2015:1002-1012.

[9] Guo J, Zhong J, Dang X, et al. Seismic Responses of a Cable-Stayed Bridge with Consideration of Uniform Temperature Load[J]. 2016, 6(12):408.

[10] Yang Y, Wang X, Wu Z. Experimental Study of Vibration Characteristics of FRP Cables for Long-Span Cable-Stayed Bridges[J]. Journal of Bridge Engineering, 2015, 20(4):04014074.

[11]Naderian H, Cheung M M S, Shen Z, et al. Integrated finite strip analysis for long-span cable-stayed bridges[J]. Computers \& Structures, 2015, 158:82-97.

[12] Wu T. Structural Design and Construction of No-backstay Cable-stayed Bridge[J]. Urban Roads Bridges \& Flood Control, 2016. 